\title{
ANÁLISES DE COR E IMAGEM DAS ROCHAS ORNAMENTAIS BUTTERFLY BEIGE, BUTTERFLY GOLD E BUTTERFLY GREEN EXPOSTAS A ALTAS TEMPERATURAS
}

\author{
COLOR AND IMAGE ANALYSIS OF BUTTERFLY BEIGE, BUTTERFLY GOLD AND \\ BUTTERFLY GREEN DIMENSION ROCKS EXPOSED TO HIGH TEMPERATURES.
Thiago Motta BOLONINI ${ }^{1}$, Antonio Misson GODOY ${ }^{2}$, Carlos Alberto Machado FIGUEIREDO $^{3}$, António MAURÍCIO ${ }^{3}$, Manuel Francisco PEREIRA ${ }^{3}$, Igor Magalhães \\ CLEMENTE $^{4}$, Francisco Diones Oliveira SILVA ${ }^{4}$ \\ ${ }^{1}$ Pós-graduação em Geologia Regional, Instituto de Geociências e Ciências Exatas, Universidade Estadual Paulista, Av. 24-A, nº \\ 1515, C. P. 178, CEP 13506-900, Rio Claro, São Paulo, Brasil. End. eletrônico: thiagotro@gmail.com. \\ ${ }^{2}$ Departamento de Petrologia e Metalogenia, Instituto de Geociências e Ciências Exatas, Universidade Estadual Paulista. End. \\ eletrônico: mgodoy@rc.gov.br \\ ${ }^{3}$ Centro de Petrologia e Geoquímica do Instituto Superior Técnico - IST, Av. Rovisco Pais no 1, 1049-001 Lisboa, Portugal. \\ carlos.m.figueiredo@ist.utl.pt, pcd2045@ist.utl.pt,mfcp@ist.utl.pt \\ ${ }^{4}$ Pós-graduação em Geologia, Universidade Federal do Ceará, Fortaleza - CE, Brasil. Avenida Mister Hull, S/N - Pici, CEP 60455- \\ 760, Fortaleza - CE. igorclemente@unipampa.edu.br,diones.geologia@yahoo.com.br \\ Introdução \\ Geologia Local \\ Materiais e Métodos \\ Resultados e Discussões \\ Conclusões \\ Agradecimentos \\ Referências
}

\begin{abstract}
RESUMO - São estudadas as rochas ornamentais Butterfly Beige, Butterfly Gold e Butterfly Green correspondentes a quartzo sienitos com hiperstênio que são exploradas em Barra de São Francisco-Espírito Santo, Brasil. O objetivo é analisar os efeitos estéticos, bem como quantificá-los, depois de submetidas à exposição de temperaturas elevadas a partir de análises comparativas das imagens, das cores e das respectivas características petrográficas. Os valores para os coeficientes de correlação $(r)$ entre as rochas, já nos primeiros $200^{\circ} \mathrm{C}$, mostram descaracterizações moderadas, sendo as rochas bastante afetadas pela temperatura. As alterações causadas pela ciclagem térmica somada à umidade aceleram o processo de oxidação do Fe. Além disso, por histerese, a ciclagem implica a geração de microfissuras e o alargamento dos planos de clivagem dos minerais, bem como ofusca os contatos entre eles, facilitando a percolação de fluidos (água) e aumentando o grau de oxidação do Fe ao mesmo tempo em que facilita a disseminação do $\mathrm{Fe}(\mathrm{OH})_{2}$. Frente aos resultados obtidos, sugere-se que as rochas estudadas (principalmente a variedade Green) sejam utilizadas em revestimentos de ambientes internos e que fontes de calor, como o sol, em revestimentos externos, podem acelerar o processo de modificação das cores em função da presença de minerais ferro-magnesianos e, principalmente, do Fe $(\mathrm{OH})_{2}$ passíveis de oxidação.

Palavras-chave: Rochas Ornamentais, Fadiga Térmica, Descaracterização Estética, Padrão de Cor RGB.
\end{abstract}

\begin{abstract}
The dimension stones are commercially known as Butterfly Beige, Butterfly Gold and Butterfly Green and correspond to quartz syenites with hypersthene that are explored in Barra de São Francisco-Espírito Santo, Brazil. The objective is to analyze the aesthetic effects and to quantify these rocks in the appearance after the exposure to elevated temperatures, from images, colors and petrographic characteristics. The values found for the correlation coefficients (r) between the rocks, already in the first $200^{\circ} \mathrm{C}$, show moderate decharacterizations, being the rocks quite affected by the temperature. Changes caused by thermal cycling combined with moisture accelerate the Fe oxidation process. In addition, by hysteresis, cycling involves the generation of microcracks and the expansion of mineral cleavage planes, as well as overshadowing the contacts between them, facilitating the percolation of fluids (water) and increasing the degree of Fe oxidation while facilitating the diffusion of $\mathrm{Fe}(\mathrm{OH})_{2}$. In view of the obtained results, it is suggested that the studied rocks (mainly the Green variety) be used in indoor coatings and that heat sources, such as the sun, in external coatings, can accelerate the process of color modification in function of the presence of iron-magnesium minerals and, especially, oxidable $\mathrm{Fe}(\mathrm{OH})_{2}$.
\end{abstract}

Keywords: Dimension Stones, Thermal Fatigue, Aesthetic Disfiguration, RGB Color Standard.

\section{INTRODUÇÃO}

As rochas ornamentais utilizadas neste trabalho são rochas quartzo sieníticas com hiperstênio denominadas comercialmente de Butterfly Beige, Butterfly Gold e Butterfly Green e são extraídas no distrito de Itaperuna, Município de Barra de São Francisco, Estado do Espírito Santo, Brasil. O objetivo é analisar os efeitos na aparência estética da rocha causados pela exposição destas rochas ornamentais às temperaturas elevadas. Ao observar rochas ígneas com hiperstênio já assentadas pode-se verificar que em algumas situações, após algum tempo de exposição, apresentam-se desbotadas e amareladas devido à oxidação do Fe.

Julga-se que o agente acelerador destas modificações de cor esteja relacionado ao aumento da temperatura devido à insolação e a 
presença de umidade, situação mais comum em ambientes externos das construções civis. Neste sentido, com o objetivo de se avaliar a influência destes efeitos nas modificações das características estéticas por parte da rocha, foram realizados estudos baseados na análise de imagens, de dados colorimétricos com o uso do padrão de cor RGB, de correlações entre imagens e de algumas características petrográficas em rochas expostas a altas temperaturas.

Ao longo dos anos, vários autores estudaram a expansão térmica de rochas e seus efeitos relacionados aos aspectos estruturais das mesmas.

Richter \& Simmons (1974), por exemplo, estudaram rochas expostas a variações de temperatura entre $25^{\circ} \mathrm{C}$ e $550^{\circ} \mathrm{C}$ em um dilatômetro e constataram que, na maioria delas, a expansão térmica se dá em função da porosidade provocada por rupturas, da taxa de aquecimento e da temperatura máxima anterior, bem como da composição mineralógica e da orientação cristalina preferencial. As rupturas por sua vez podem ser geradas, não pelo aquecimento, mas sim pela taxa de arrefecimento à qual a amostra analisada é submetida.

Torok \& Hajpal (2005), ao estudarem arenitos constataram que, no caso de um incêndio em um edifício revestido com as rochas analisadas, o comprometimento da estrutura de rochas pode partir de rupturas termais geradas, não a partir do incêndio, mas sim pelo resfriamento rápido causado pela utilização, por exemplo, de água no combate ao fogo.
A deterioração causada pela temperatura compreende processos relacionados com o aquecimento por radiação dos materiais: a chamada "meteorização por insolação" e a deterioração produzida pelo fogo.

Estes processos físicos correspondem a dois modelos de meteorização termicamente induzida: a fadiga térmica e o choque térmico (Winkler, 1977; Yatsu, 1998; Heras, 2005).

Aires-Barros et al. (1975) realizaram testes de fadiga térmica em rochas ígneas por insolação induzida à luz, rochas estas caracterizadas no trabalho de Griggs (1936), que estudou variações de $110^{\circ} \mathrm{C}$, simulando um período de 244 anos de insolação em rochas com diferentes texturas e que, com base em observações petrográficas e utilizando técnicas de fotografia, chegou à conclusão de que não houve mudanças percebidas nas superfícies das rochas frente às solicitações térmicas que sofreram.

A análise de imagem é utilizada para avaliar rochas ornamentais por diversos autores (Figueiredo et al., 2005; Vasquez, 2011; Torquato et al., 2008) e vem se mostrando uma importante ferramenta para quantificação de alterações superficiais causadas por fenômenos físicos e/ou químicos em placas pétreas para uso da construção civil.

Diante disso faz-se uso desta ferramenta na avaliação dos efeitos causados pelas altas temperaturas nestas rochas brasileiras (Bolonini, 2015; Bolonini \& Godoy, 2017; Bolonini et al., 2013; Saar, 2013, 2015; Bolonini et al., 2016a; 2016b, 2016c).

\section{GEOLOGIA LOCAL}

As rochas estudadas são extraídas em um maciço que aflora sob a forma de um corpo intrusivo alongado, com aproximadamente $35 \mathrm{~km}$ de eixo maior de direção NE-SW, localizado no município de Barra de São Francisco, estado do Espírito Santo (Figura 1).

Este corpo intrusivo insere-se no contexto do Orógeno Araçuaí (Pedrosa-Soares et al., 1992, 2001, 2006, 2007; Martins et al., 2004; Marshak et al., 2006; Alkimin et al., 2007; Noce et al., 2007; CPRM, 2007) que, segundo texto publicado pela CPRM (2007), guarda marcantes evidências dos estágios pré-colisional (630-585 $\mathrm{Ma}$ ), sin-colisional (585-560 Ma), tardi-colisional (560-535 Ma) e pós-colisional (530-490 Ma).

No estágio pré-colisional (630-585 Ma), acrescionário, foi edificado um arco magmático cálcio-alcalino em ambiente de margem continental ativa, constituída por batólitos tonalíticos a granodioríticos ricos em autólitos dioríticos e máficos, deformados, que registram a foliação regional em fácies anfibolito a granulito. Denominações locais desta suíte são Galileia, São Vítor, Mascarenhas e além de outras.

Entre os estágios pré-colisional e sin-colisional ocorreu sedimentação dos protólitos do complexo paragnáissico da região setentrional do Espírito Santo, que contém zircões detríticos com idades entre 630 e $600 \mathrm{Ma}$.

A rocha predominante neste complexo é um gnaisse peraluminoso (rico em granada, cordierita e/ou sillimanita) que atingiu 
metamorfismo da fácies granulito. Na região da Folha de Mantena - MG, as unidades aflorantes do Orógeno correspondem a Supersuítes G5 (Cambriano) e G2 (Neoproterozóico) (PedrosaSoares et al., 2006).
Os autores, em 2007, classificam as Supersuítes como Suíte G5 (Cambriano), na qual o corpo intrusivo de onde são extraídas as rochas utilizadas neste estudo está inserido e Suíte G2 (Neoproterozoico), como mostra a figura 1.

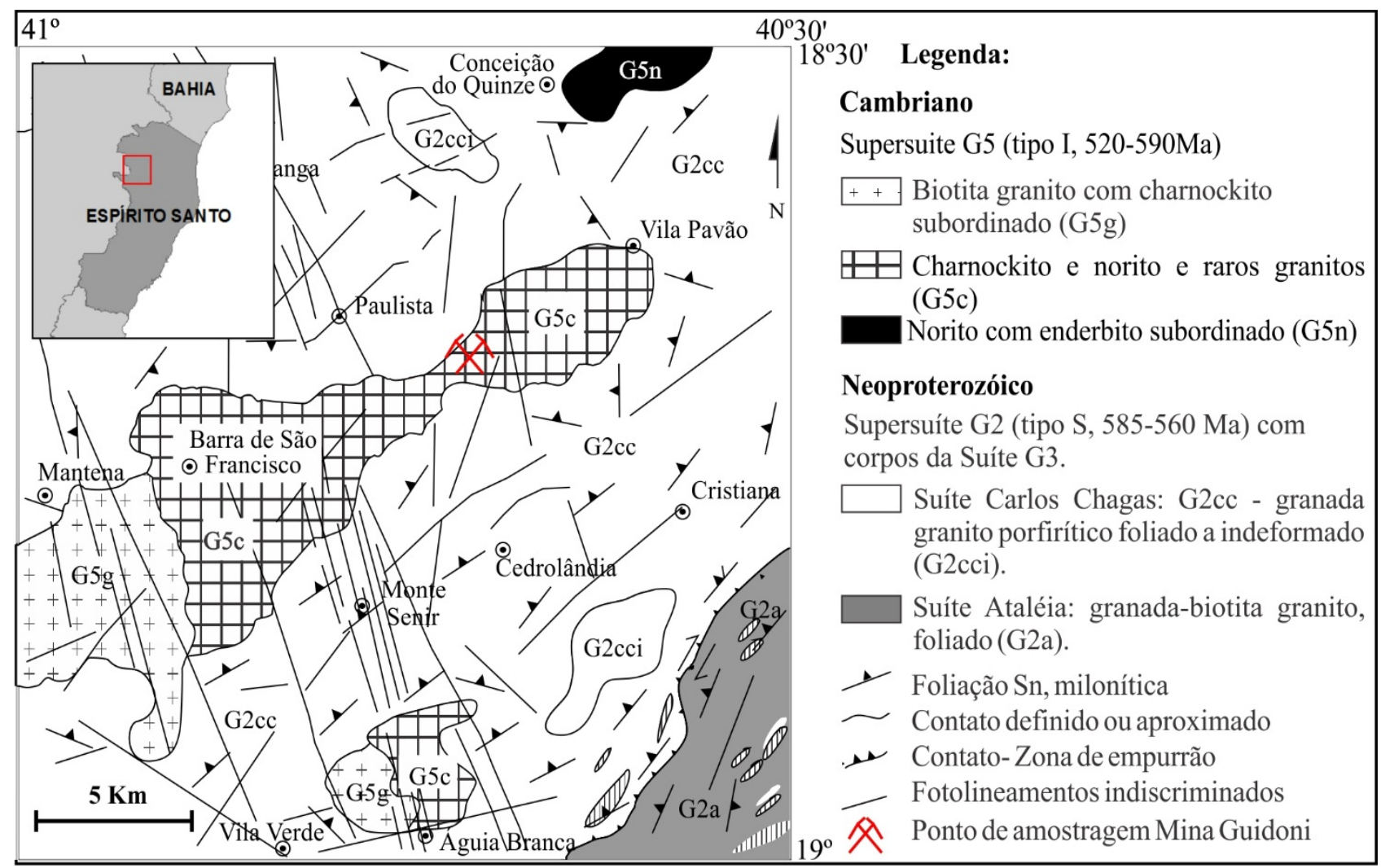

Figura 1 - Mapa geológico, adaptado, da folha Mantena-MG. (Mod. de Pedrosa-Soares et al., 2006).

Roncato Júnior (2009), entretanto, coloca o Orógeno Araçuaí subdivido, na região da folha geológica de Mantena-MG, entre a Cambriana Suíte Intrusiva Aimorés (charnockito) e a Neoproterozóica Suíte Carlos Chagas (deformada). Tais subdivisões classificam de forma particular o mesmo conjunto de rochas.

A suíte G5, de maneira geral, é constituída de intrusões graníticas do Tipo I, livres da foliação regional, cuja ocorrência se limita ao núcleo do orógeno. Estas intrusões podem conter fácies charnockíticas e enderbíticas.

$\mathrm{Na}$ porção sul do orógeno, em decorrência da exposição de nível crustal mais profundo, são comuns os plútons zonados que mostram núcleos (raízes) de composição básica. A composição predominante das intrusões G5 varia de monzogranito a sienogranito, geralmente porfirítico, com enclaves máficos e eventuais xenólitos de rocha encaixante (Almeida, 2004).

\section{MATERIAIS E MÉTODOS}

Os tipos litológicos polidos utilizados neste trabalho são extraídos no distrito de Itaperuna, Município de Barra de São Francisco, Estado do Espírito Santo, Brasil. Todas as três rochas utilizadas neste trabalho correspondem a quartzo sienitos com hiperstênio.

O Butterfly Beige (Figura 2A) corresponde a uma rocha de textura fanerítica inequigranular, hipidiomórfica, com granulação grossa a porfirítica, com cristais que variam de $0,2 \mathrm{~cm}$ a $4,5 \mathrm{~cm}$, de coloração geral bege, estrutura isotrópica, composta por microclínio (62\%), plagioclásio (22\%), quartzo (11\%), granada (3\%) biotita e hiperstênio (2\%).

O Butterfly Gold (Figura 2B), rocha de textura fanerítica inequigranular, hipidiomórfica, de granulação grossa a porfirítica com cristais que variam de $0,2 \mathrm{~cm}$ a $4,5 \mathrm{~cm}$, de coloração geral marrom/dourada (ferruginosa), estrutura isotrópica, composta por microclínio (58\%), plagioclásio (20\%), quartzo (15\%), granada (2\%) biotita e hiperstênio (3\%). 
O Butterfly Green (Figura 2C), também corresponde um hiperstênio-quartzo sienito, alotriomórfica, de textura fanerítica inequigranular, de granulação grossa a porfirítica com cristais que variam de $0,2 \mathrm{~cm}$ a $4 \mathrm{~cm}$, de coloração verde, estrutura isotrópica, composta dominantemente por microclínio (58\%), plagioclásio (oligoclásio) (20\%), quartzo (13\%), granada (6\%), biotita e hiperstênio (3\%).

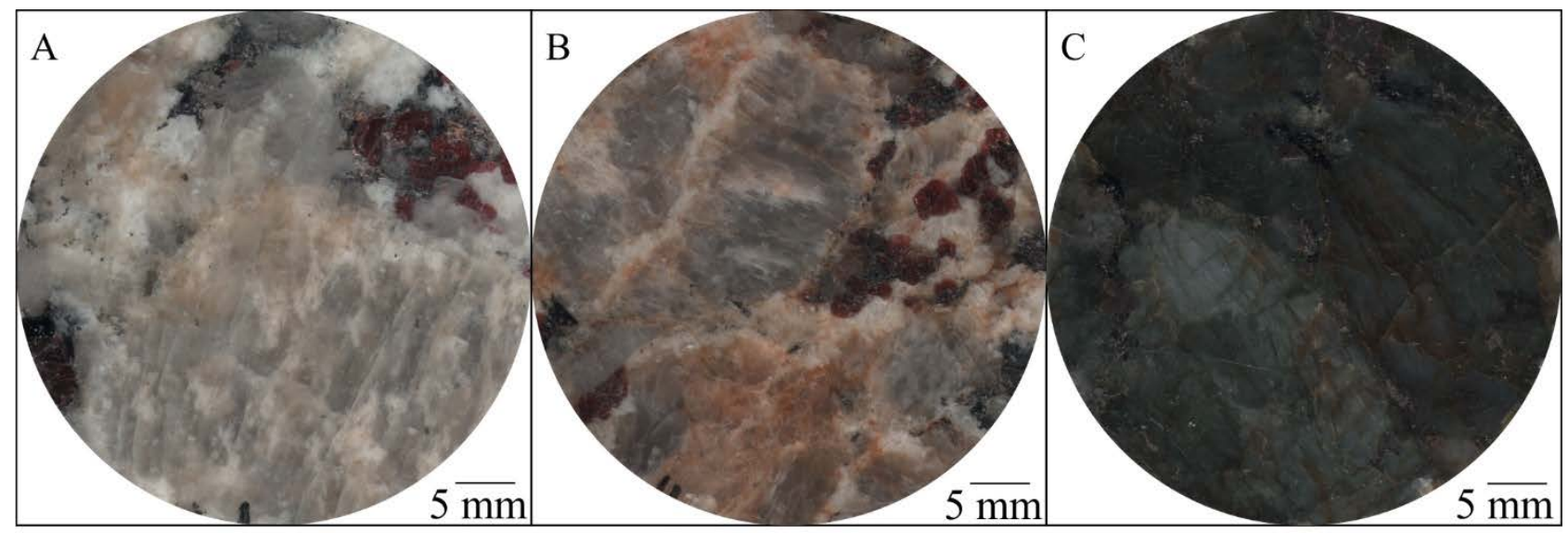

Figura 2 - Digitalizações das superfícies polidas dos litotipos ensaiados. A) Butterfly Beige; B) Butterfly Gold; C) Butterfly Green

Os corpos de prova (discos de rocha) possuem uma de suas faces polida e dimensões de 4,5 cm de diâmetro e 1,5 cm de altura e foram utilizados dois para cada tipo de rocha. Os corpos de prova do Butterfly Gold possuem ainda uma face telada.

Para realização do experimento os corpos de prova analisados foram inseridos em um forno Hearaeous Electronic, de propriedade do Centro de Petrologia e Geoquímica do Instituto Superior Técnico - CEPGIST/ Lisboa, Portugal.

As amostras de rocha foram inseridas no forno conforme a tabela 1, que mostra a configuração do experimento com os respectivos valores de tempo $(\mathrm{t})$, temperatura (T) e número de exposições às quais as rochas foram submetidas.

Tabela 1 - Configuração do experimento, tempos, temperaturas e números de exposições.

\begin{tabular}{|c|c|c|c|c|c|c|c|c|c|c|}
\hline \multicolumn{2}{|c|}{ Exp. $n^{\circ}$} & $n^{0}$ cdp & $\mathbf{t}_{\mathbf{e}}$ & $\mathbf{t}_{\mathbf{a}}$ & $\mathbf{t}_{\text {eac }}$ & \multicolumn{2}{|c|}{$\mathbf{t}_{\mathrm{aac}}$} & $\mathbf{t}_{\mathrm{act}}$ & $\mathbf{T}$ & $\mathbf{T}_{\mathrm{ac}}$ \\
\hline \multicolumn{2}{|l|}{1} & 8 & 1440 & 30 & 1440 & \multicolumn{2}{|c|}{30} & 1470 & 72 & 72 \\
\hline \multicolumn{2}{|l|}{2} & 6 & 60 & 30 & 1500 & \multicolumn{2}{|c|}{60} & 1560 & 200 & 272 \\
\hline \multicolumn{2}{|l|}{3} & 4 & 60 & 30 & 1560 & \multicolumn{2}{|c|}{90} & 1650 & 400 & 672 \\
\hline \multicolumn{2}{|l|}{4} & 2 & 60 & 30 & 1620 & \multicolumn{2}{|c|}{120} & 1740 & 600 & 1272 \\
\hline \multicolumn{2}{|c|}{ Legenda: } & \multicolumn{9}{|c|}{ Tempo em miutos e temperatura em ${ }^{\circ} \mathrm{C}$. } \\
\hline Exp. $\mathbf{n}^{0}$ & $=$ & \multicolumn{4}{|c|}{ número da exposição } & $t_{\text {aac }}$ & $=$ & \multicolumn{3}{|c|}{ tempo de arrefecimento acumulado } \\
\hline $\mathbf{t}_{\mathbf{e}}$ & $=$ & \multicolumn{4}{|c|}{ tempo de exposição } & $\mathbf{t}_{\mathrm{act}}$ & $=$ & \multicolumn{3}{|c|}{ tempo acumulado total } \\
\hline $\mathbf{t}_{\mathbf{a}}$ & $=$ & \multicolumn{4}{|c|}{ tempo de arrefecimento } & $\mathbf{T}$ & $=$ & \multicolumn{3}{|l|}{ temperatura } \\
\hline $\mathbf{t}_{\text {eac }}$ & $=$ & \multicolumn{4}{|c|}{ tempo de exposição acumulado } & $\mathbf{T}_{\mathrm{ac}}$ & $=$ & \multicolumn{3}{|c|}{ temperatura acumulada } \\
\hline$n^{0}$ cdp & $=$ & \multicolumn{4}{|c|}{ corpos de prova por rocha } & & & & & \\
\hline
\end{tabular}

Para cada exposição subsequente foram retirados dois corpos de prova, restando no fim apenas dois discos por litotipo que passaram por todas as exposições $\left(72^{\circ} \mathrm{C}\right.$ a $\left.600^{\circ} \mathrm{C}\right)$ e somente um deles foi submetido à análise de imagem. A temperatura de $72^{\circ} \mathrm{C}$ foi utilizada para a secagem da amostra.

Os primeiros passos a serem dados foram então a pesagem e a digitalização das superfícies dos mesmos antes do experimento.
Em seguida, as amostras passaram pela temperatura de $72^{\circ} \mathrm{C}$ para secagem $(24 \mathrm{~h}$ ou 1440 minutos) e obtenção da massa constante, ou seja, para certificar-se de que a diferença entre duas pesagens no intervalo de $24 \mathrm{~h}$ não excederia $0,1 \%$.

Em um segundo instante as amostras passaram por um resfriamento de 30 minutos à temperatura ambiente. Na sequência foram realizadas novas digitalizações das superfícies 
dos corpos de prova.

A partir deste ponto, estes procedimentos (aquecimento por 60 minutos, resfriamento por 30 minutos e digitalização) foram repetidos para as temperaturas de $200^{\circ} \mathrm{C}$, para de $400^{\circ} \mathrm{C}$ e para de $600^{\circ} \mathrm{C}$.

A digitalização das superfícies foi feita com o uso de uma impressora multifuncional Epson com resolução máxima de 600 dpi e imagens salvas no formato TIFF (Tagged Image File Format), no padrão de cor RGB (Red, Green, Blue), em 24 bits e também em 8bits (escala de cinza) para medição de cor e correlação entre imagens respectivamente.

Para evitar possíveis "ruídos" de borda, devidos às imperfeições nos cortes feitos pela coroa diamantada no momento da confecção dos discos de rocha, as imagens foram cortadas no software Corel DRAW, com 4,2 cm de diâmetro (Figura 3A), descartando uma coroa circular com diferença entre os diâmetros (interno e externo) de $0,3 \mathrm{~cm}$. A medição de cor RGB foi feita com o uso dos plugins: $R G B$ Profile Plot e Measure RGB, nas imagens RGB 24bits.

Para tanto foi analisado um corpo de prova por rocha e para cada temperatura da seguinte forma: foram confeccionados dois perfis (RGB Profile Plot) para cada superfície analisada (Figura 3A) e uma medição geral na totalidade da área recortada (Measure $R G B$ ).

Os resultados obtidos com a medição em perfis RGB são mostrados como na figura 3B, com o início do perfil à esquerda (P1 e P2) e o fim do perfil à direita (P1' e P2'). O pedaço de imagem, sob a linha branca que demarca o perfil, mostra o local exato por onde o perfil passou.

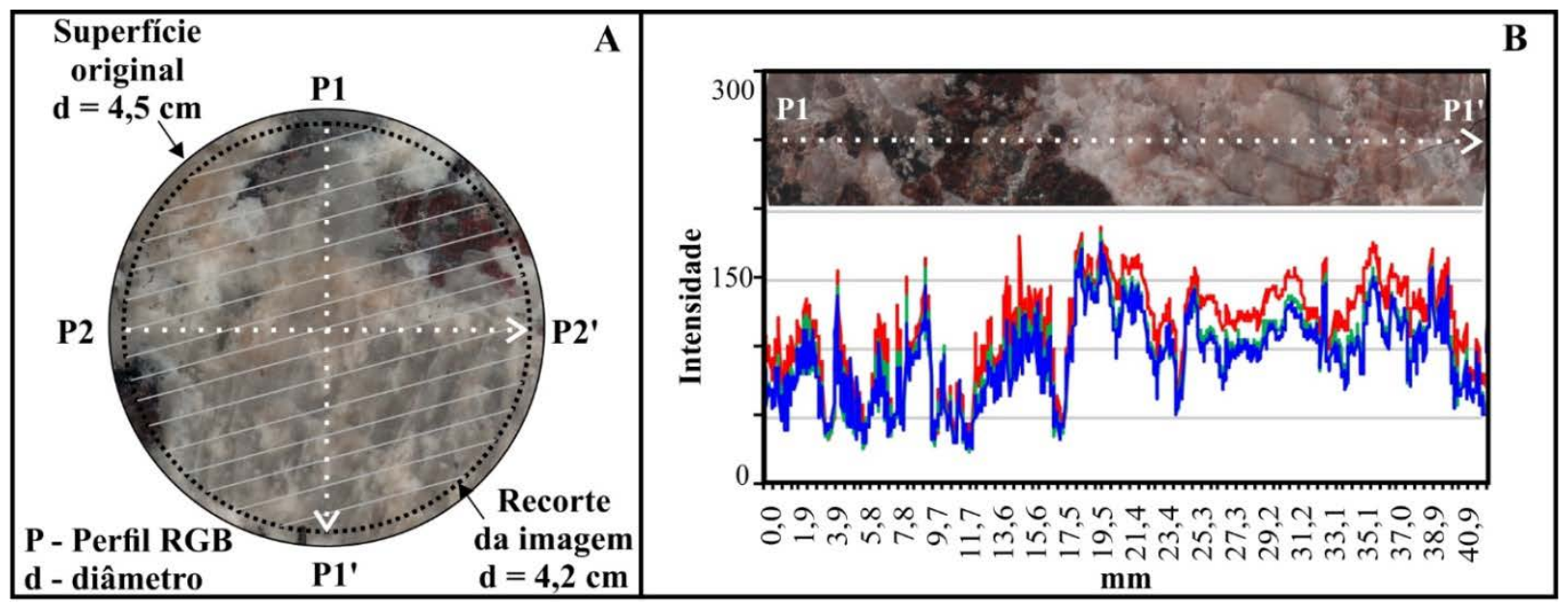

Figura 3 - Esquema de corte dos corpos de prova e o posicionamento dos perfis. A área listrada em (A) indica a medição de RGB realizada na totalidade da área recortada

Para análise de correlação entre imagens foi utilizado o plugin Image Correlator do software ImageJ, nas imagens 8bits em escala de cinza, cujo esquema de correlação entre as imagens se encontra na figura 4, usando uma possível correlação entre imagens de corpos de prova expostos a $72^{\circ} \mathrm{C}$ e $200^{\circ} \mathrm{C}$.

Basicamente, o software compara um pixel de determinada localização na imagem com outro pixel, de mesma localização, na imagem com a qual se deseja fazer a correlação. O software oferece também uma tabela com esses valores de pixels das imagens correlacionadas.

De posse dos valores fornecidos pelo plugin, em forma de tabela, foi calculado o coeficiente de correlação linear de Pearson ( $\boldsymbol{r}$ ) através da equação, para determinar o quão correla- cionadas estarão, com seus originais (aos $72^{\circ} \mathrm{C}$ ), as imagens oriundas das digitalizações dos corpos de prova dos litotipos expostos às diferentes temperaturas $\left(200^{\circ} \mathrm{C}, \quad 400^{\circ} \mathrm{C}\right.$ e $\left.600^{\circ} \mathrm{C}\right)$.

$$
r=\frac{\sum(x-\bar{x})(y-\bar{y})}{\sqrt{\sum(x-\bar{x})^{2} \sum(y-\bar{y})^{2}}} \quad r \in[-\mathbf{1}, \mathbf{1}]
$$

Onde: $\boldsymbol{x}=$ valor do pixel na imagem ao natural; $\overline{\boldsymbol{x}}=$ média aritmética para os valores dos píxels na imagem ao natural; $\boldsymbol{y}=$ valor do píxel na imagem que se quer correlacionar; $\overline{\boldsymbol{y}}=$ média aritmética para os valores dos pixels na imagem que se quer correlacionar.

O grau de correlação entre imagens pode ser avaliado, de acordo com o valor obtido a partir 
da equação 1 e quanto ao grau de descaracterização superficial das rochas, com base na tabela 2, adaptadas de Souza (2008), Cohen (1988); Dancey \& Reidy (2005).

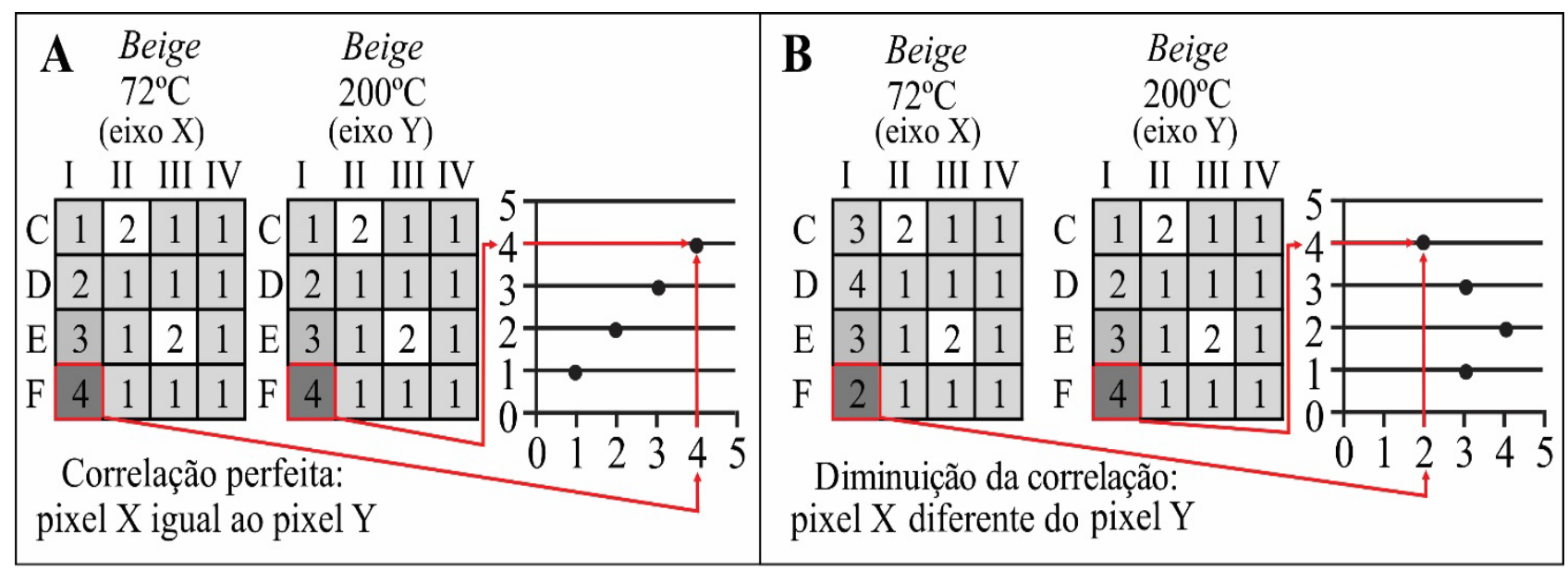

Figura 4 - Esquema de comparação entre imagens do Plugin Image Correlator, ImageJ.

Tabela 2 - Classificação relacionada ao coeficiente de correlação de Pearson.

\begin{tabular}{c|c|c}
\hline Coeficiente de Correlação Linear de Pearson $(\boldsymbol{r})$ & Correlação & Descaracterização da rocha \\
\hline $\mathbf{r}=\mathbf{1}$ & Perfeita Positiva & Nula \\
\hline $\mathbf{0 , 8} \leq \mathbf{r}<\mathbf{1}$ & Forte positiva & Fraca \\
\hline $\mathbf{0 , 5} \leq \mathbf{r}<\mathbf{0 , 8}$ & Moderada positiva & Moderada \\
\hline $\mathbf{0 , 1} \leq \mathbf{r}<\mathbf{0 , 5}$ & Fraca positiva & Considerável \\
\hline $\mathbf{0}<\mathbf{r}<\mathbf{0 , 1}$ & Ínfima positiva & Forte \\
\hline $\mathbf{0}$ & Nula & Total descaracterização \\
\hline $\mathbf{- 0 , 1}<\mathbf{r}<\mathbf{0}$ & Ínfima negativa & Forte \\
\hline $\mathbf{- 0 , 5}<\mathbf{r} \leq-\mathbf{0 , 1}$ & Fraca negativa & Considerável \\
\hline $\mathbf{- 0 , 8}<\mathbf{r} \leq-\mathbf{0 , 5}$ & Moderada negativa & Moderada \\
\hline$-\mathbf{1}<\mathbf{r} \leq-\mathbf{0 , 8}$ & Forte negativa & Fraca \\
\hline $\mathbf{r}=-\mathbf{1}$ & Perfeita negativa & Nula \\
\hline
\end{tabular}

\section{RESULTADOS E DISCUSSÃO}

Após serem expostas a todas as temperaturas e serem medidas as propriedades de cor, na figura 5 é possível fazer uma análise visual das modificações causadas aos corpos de prova pelas exposições às temperaturas de $72^{\circ} \mathrm{C}$, $200^{\circ} \mathrm{C}, 400^{\circ} \mathrm{C}$ e $600^{\circ} \mathrm{C}$.

De forma introdutória, apenas pela análise visual e já fazendo uma alusão à colorimetria, nota-se que os corpos de prova do Butterfly Beige e Butterfly Gold (Figuras 5A e 5B) ficaram "escuros" dos $72^{\circ} \mathrm{C}$ aos $600^{\circ} \mathrm{C}$. O Butterfly Green (Figura 5C), por sua vez, apresentou-se mais "castanho" à medida que a temperatura aumentou, perdendo sua cor verde característica.

A tabela 3 apresenta os resultados oriundos das leituras RGB e coeficientes de correlação entre imagens em diferentes temperaturas de exposição.

Dos $72^{\circ} \mathrm{C}$ para os $200^{\circ} \mathrm{C}$ o Butterfly Green foi a rocha com a maior descaracterização, ou seja, a menor correlação com sua imagem ao natural apresentando uma descaracterização moderada $(\boldsymbol{r}=0,5)$, seguido do Butterfly Gold $(\boldsymbol{r}=0,6)$ e do Butterfly Beige $(\boldsymbol{r}=0,7)$ ainda no campo da descaracterização moderada.

Entretanto, à medida que se aumenta a temperatura para $400^{\circ} \mathrm{C}$ e para $600^{\circ} \mathrm{C}$ percebese que todos os litotipos respondem de maneira similar (Tabela 3 e Figura 6), ficando todos) dentro do campo de descaracterização moderada $(0,5 \leq \boldsymbol{r}<0,8)$.

Isto se deve ao fato das distribuições e composições mineralógicas dessas rochas serem muito similares. Houve uma mudança de cor, para todos os litotipos, evidenciada nas 
imagens relativas às exposições aos $400^{\circ} \mathrm{C}$ e aos $600^{\circ} \mathrm{C}$.

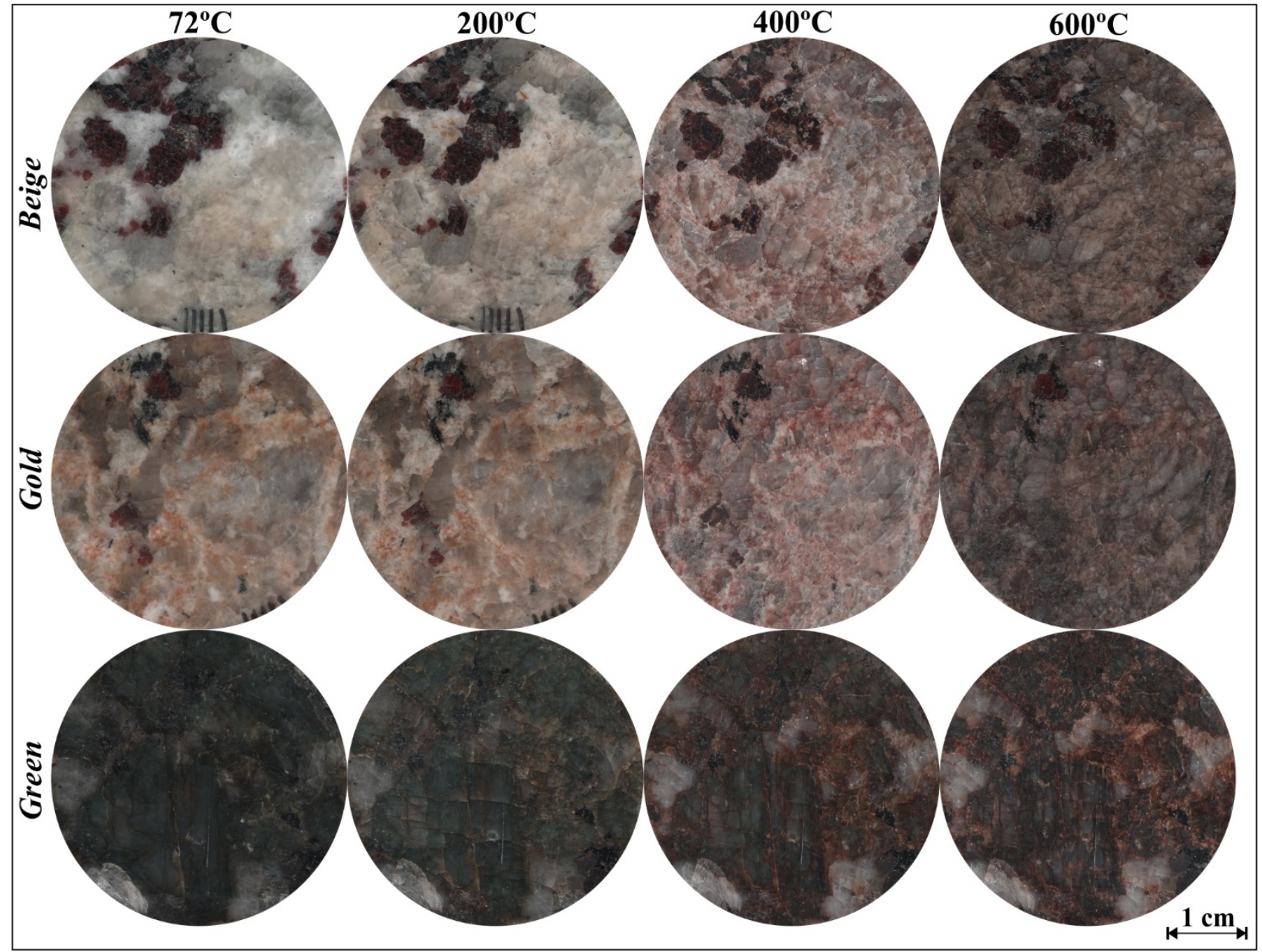

Figura 5 - Ilustração das modificações estéticas causadas às rochas pelas exposições a diferentes temperaturas.

Tabela 3 - Média das Leituras RGB (área) e coeficientes de correlações entre as imagens.

\begin{tabular}{|c|c|c|c|c|c|c|c|c|c|c|c|}
\hline \multirow[b]{2}{*}{ Amostra } & \multicolumn{8}{|c|}{ RGB } & \multicolumn{3}{|c|}{ Coeficiente de correlação $(r)$ entre as imagens } \\
\hline & \multicolumn{2}{|c|}{$72^{\circ} \mathrm{C}$} & \multicolumn{2}{|c|}{$200^{\circ} \mathrm{C}$} & \multicolumn{2}{|c|}{$400^{\circ} \mathrm{C}$} & \multicolumn{2}{|c|}{$600^{\circ} \mathrm{C}$} & $7^{\circ}{ }^{\circ} \mathrm{C}$ e $200^{\circ} \mathrm{C}$ & $72^{\circ} \mathrm{C}$ e $400^{\circ} \mathrm{C}$ & $72^{\circ} \mathrm{C}$ e $600^{\circ} \mathrm{C}$ \\
\hline \multirow{3}{*}{ Beige } & $\mathrm{R}$ & 125 & $\mathrm{R}$ & 125 & $\mathrm{R}$ & 83 & $\mathrm{R}$ & 119 & \multirow{3}{*}{0,7} & \multirow{3}{*}{0,5} & \multirow{3}{*}{0,5} \\
\hline & G & 119 & G & 115 & G & 71 & G & 102 & & & \\
\hline & B & 114 & B & 108 & B & 67 & B & 98 & & & \\
\hline \multirow{3}{*}{ Gold } & $\mathrm{R}$ & 120 & $\mathrm{R}$ & 122 & $\mathrm{R}$ & 82 & $\mathrm{R}$ & 124 & \multirow{3}{*}{0,6} & \multirow{3}{*}{0,6} & \multirow{3}{*}{0,5} \\
\hline & G & 102 & G & 104 & G & 71 & G & 104 & & & \\
\hline & $\mathrm{B}$ & 92 & B & 94 & B & 68 & B & 100 & & & \\
\hline \multirow{3}{*}{ Green } & $\mathrm{R}$ & 46 & $\mathrm{R}$ & 59 & $\mathrm{R}$ & 66 & $\mathrm{R}$ & 71 & \multirow{3}{*}{0,5} & \multirow{3}{*}{0,5} & \multirow{3}{*}{0,5} \\
\hline & $G$ & 48 & $G$ & 59 & G & 57 & $G$ & 60 & & & \\
\hline & B & 46 & B & 55 & B & 54 & B & 58 & & & \\
\hline
\end{tabular}

Para o Butterfly Beige e Butterfly Gold houve um escurecimento com a redução de intensidade de cor RGB (Tabela 3) que pode estar relacionada à presença de hidróxido de ferro no interior dos planos de clivagem dos cristais de microclínio em que, à medida que se aumenta a temperatura, maior se torna o grau de oxidação deste composto que por consequência altera a cor da rocha e as correlações entre as imagens ao natural $\left(72^{\circ} \mathrm{C}\right)$ e as imagens expostas às temperaturas de $200^{\circ} \mathrm{C}$, $400^{\circ} \mathrm{C}$ e $600^{\circ} \mathrm{C}$. Esse efeito também pode estar associado à oxidação de minerais ferromagnesianos como a biotita e o hiperstênio.

Para o Butterfly Green os valores RGB, por se tratar de uma rocha naturalmente escura, não são muito alterados mediante elevação da temperatura. 
Cabe apenas considerar que a medida que se aumenta a temperatura, ocorre a diferença do canal vermelho em relação aos demais, o que também se atribui à presença do Fe $(\mathrm{OH})_{2}$, contido nos planos de clivagem (Figura 7) e já oxidado pelo calor e pela umidade à qual está rocha foi exposta durante o período destinado ao arrefecimento.

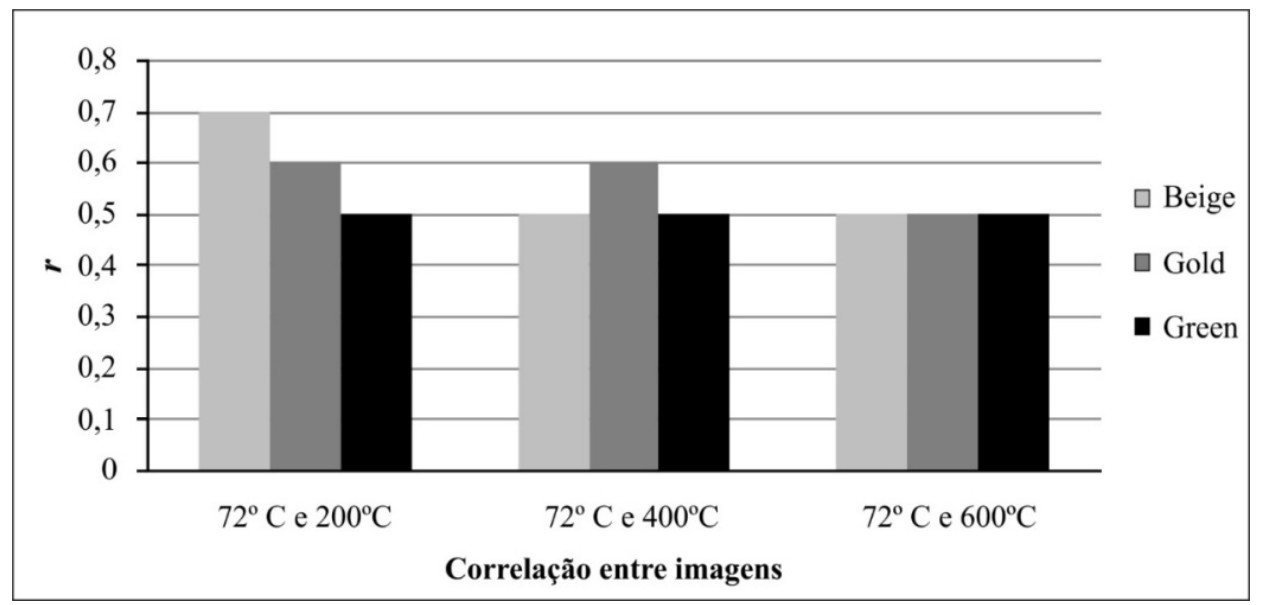

Figura 6 - Correlações entre imagens de rochas expostas à diferentes temperaturas.

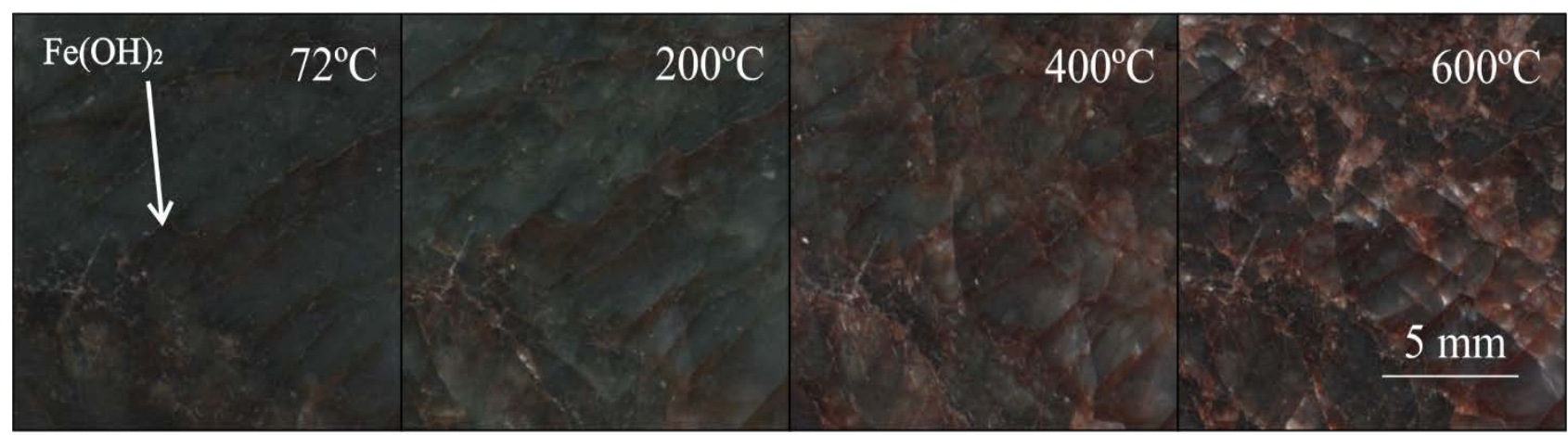

Figura 7 - Planos de clivagem preenchidos por $\mathrm{Fe}(\mathrm{OH})_{2}$ no Butterfly Green. Aumento do grau de oxidação em função do aumento da temperatura.

$\mathrm{O}$ aumento da temperatura, somado à umidade à qual os corpos de prova foram expostos durante o período de arrefecimento de 30 min (Tabela 1), acelera o processo de oxidação do Fe.

Além disso, a variação da temperatura leva a rocha a uma sucessão de ciclos de dilatação e contração que, por consequência, implica na geração de microfissuras, alargamento dos planos de clivagem dos minerais, bem como ofusca os contatos entre eles facilitando a percolação de fluidos (água) aumentando o grau de oxidação do Fe ao mesmo tempo em que facilita a disseminação do hidróxido de Fe. Com o passar do tempo, o processo todo conduz a desagregação da rocha.

Os perfis RGB dos corpos de prova permitem caracterizar as intensidades aproximadas de cada mineral ao natural facilitando a interpretação dos resultados das medições RGB ao longo das exposições às diferentes temperaturas (Figura 8).
Para o tipo litológico Butterfly Beige aos $72^{\circ} \mathrm{C}$, ou seja, ao natural, os perfis 1 e 2 (Figuras 9A e 9B) permitem estimar as intensidades RGB para os diferentes minerais que os interceptam.

Os perfis 1 e 2 apresentam o quartzo (Qtz) com valores próximos de 100, a biotita e o ortopiroxênio (Bt/Opx) com valores próximos a 0 , a granada (Grt) com valores próximos de 50 , os cristais de microclínio (Mc) com leituras de aproximadamente 125 e o plagioclásio (Pl) com valores próximos a 200 de intensidade de cor RGB.

Diante dos valores aproximados é possível fazer analogias e interpretar como cada mineral se comporta à medida que se aumenta a temperatura.

Quando analisadas as imagens dos corpos de prova expostos aos $200^{\circ} \mathrm{C}$ (Figuras 9C e 9D) percebe-se que as mudanças atingem o canal vermelho, dando um tom castanho ou ferruginoso a esta rocha. 


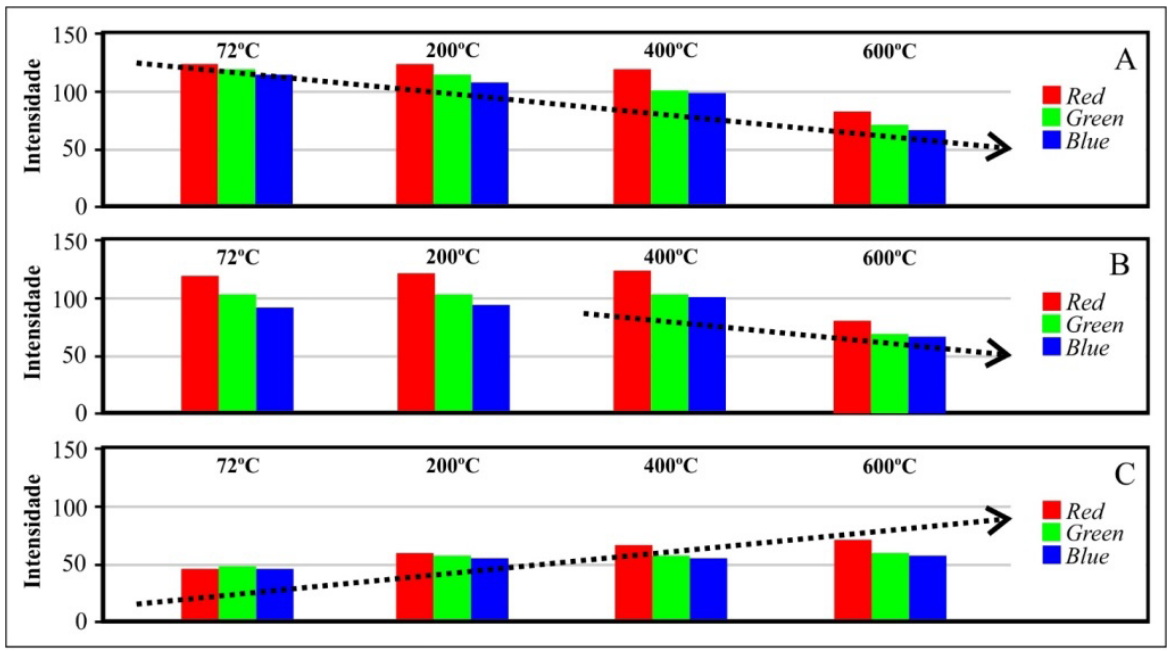

Figura 8 - Leituras RGB (área) para amostras dos quartzo sienitos com hiperstênio estudados expostas às diferentes temperaturas. Evolução das cores ao longo do aquecimento. A) Butterfly Beige; B) Butterfly Gold; C) Butterfly Green

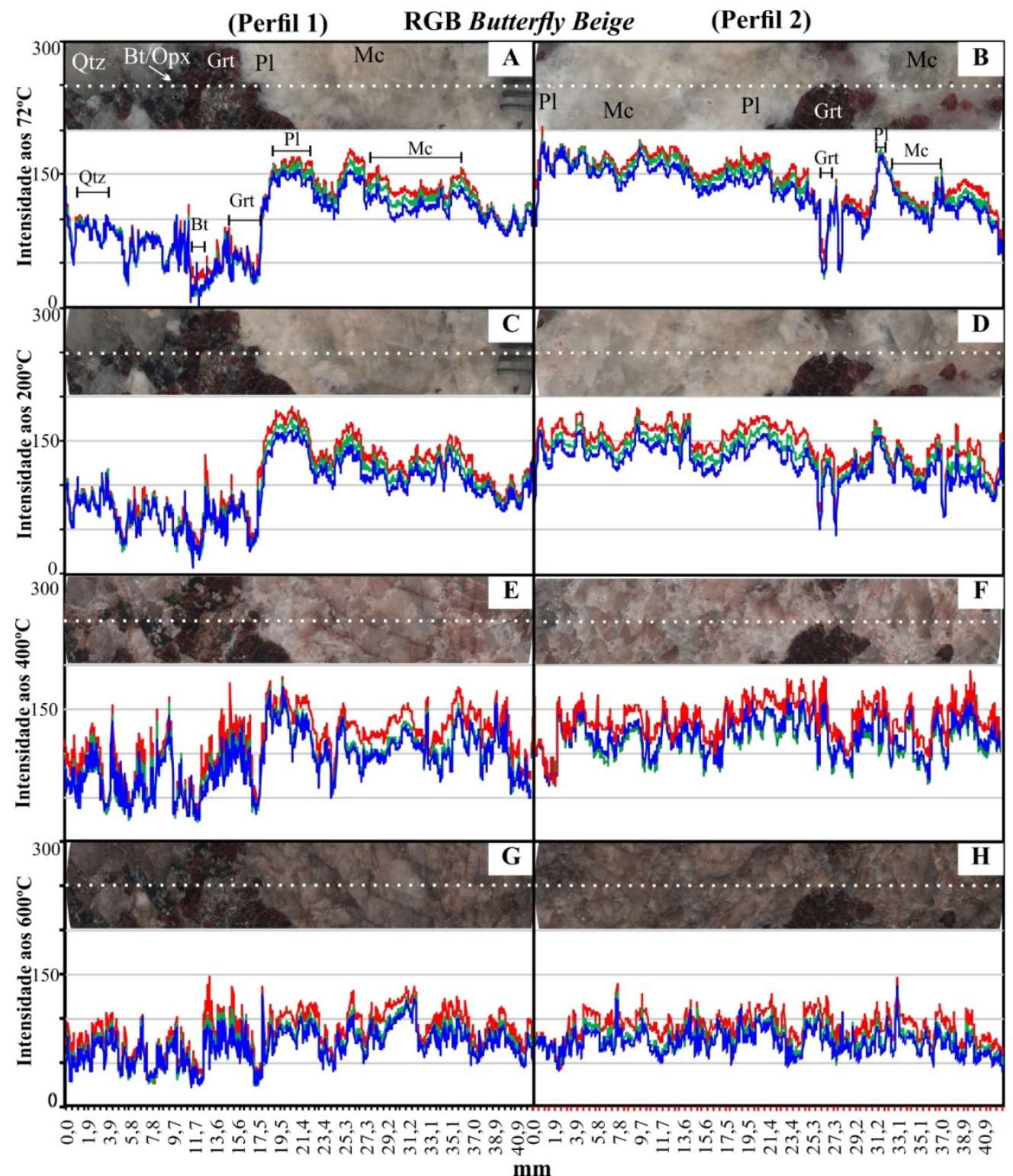

Figura 9 - Leituras dos perfis RGB para o Butterfly Beige para diferentes temperaturas.

Aos $400^{\circ} \mathrm{C}$ (Figuras 9E e 9F) ocorre que minerais escuros como a biotita e a granada significativa modificação de cor fazendo com passassem a ficar mais claros, saindo de 
aproximadamente 0 e 50 para 50 a 100 de intensidade, respectivamente devido sobretudo à oxidação pela exposição à umidade durante o resfriamento. Aos $600^{\circ} \mathrm{C}$ (Figuras 9G e 9H) este processo se intensifica dando a coloração escura visualizada na figura 6 e corroborando o escurecimento evidenciado pela diminuição dos valores de intensidade RGB na figura 9.

No Butterfly Gold as intensidades de cor RGB que diferenciam os minerais ficam mais próximas devidas ao grau de intemperismo em que se encontra a rocha.

A percolação de água fez com que minerais como a biotita fossem oxidados manchando todos os minerais adjacentes.
Esse é um fator que justifica inclusive a necessidade de telagem deste litotipo. Como pode ser visualizado nas figuras $10 \mathrm{~A}$ e $10 \mathrm{~B}$, o quartzo (Qtz) apresenta (aos $72^{\circ}$ ) valores RGB entre 50 e 100 e os feldspatos microclínio (Mc) e plagioclásio $(\mathrm{Pl})$ apresentam valores entre 50 e 100 e entre 125 e 175, respectivamente (Figura 10A e 10B).

Aos $200^{\circ} \mathrm{C}$ (Figuras 10C e 10D) o Butterfly Gold apresenta alterações cromáticas que definem o início de uma homogeneização das intensidades RGB entre os minerais, ou seja, as cores começam a se igualar entre si e a ofuscar as relações de contato entre os diversos minerais.

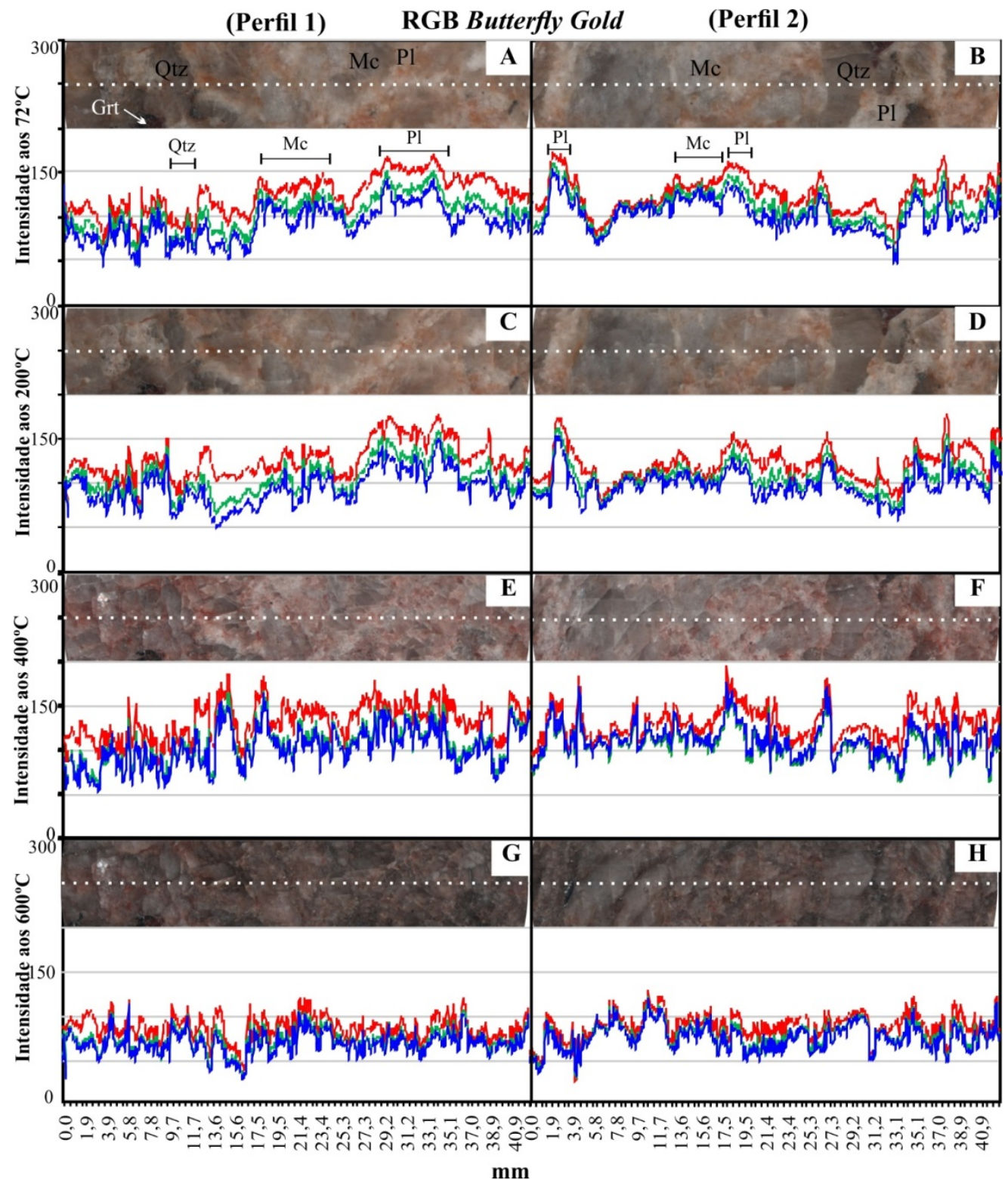

Figura 10 - Leituras dos perfis RGB para o Butterfly Gold para diferentes temperaturas.

Aos $400^{\circ} \mathrm{C}$ (Figuras 10E e 10F) o efeito percebido no Butterfly Beige também é verificado com os minerais como o microclínio (Mc), sofrendo uma diminuição na intensidade 
das leituras RGB de 150 para 100 e de plagioclásios $(\mathrm{Pl})$ diminuindo de 170 para valores próximos de 100 . Aos $600^{\circ} \mathrm{C}$ (Figuras $10 \mathrm{G}$ e $10 \mathrm{H}$ ) a intensidade relativa ao canal vermelho aumentou devido às alterações sofridas pelo hidróxido de ferro presente nos minerais e com potencial influência da queima da tela e da resina utilizadas para aumentar a resistência deste litotipo.

O Butterfly Green, por se tratar de uma rocha naturalmente escura, possui intensidades de RGB bem inferiores aos demais litotipos estudados. Aos $72^{\circ} \mathrm{C}$ (Figuras 11A e 11B) ou ao natural, o Butterfly Green apresenta minerais de coloração escura com a maioria deles apresentando intensidades RGB entre 10 e 50 como o microclínio (Mc) e biotita (Bt), com exceção do quartzo (Qtz) que apresenta valores aproximados de 75 .

Aos $200^{\circ} \mathrm{C}$ (Figuras 11C e 11D), os cristais como o microclínio (Mc-Perfil 1) e o quartzo (Qtz - Perfil 2) sofrem um pequeno aumento de intensidade RGB (cerca de 25) ficando mais claros. A esta temperatura a estrutura da rocha começa a se abrir devido ao rápido resfriamento, criando fraturas e liberando óxidos que preenchem planos de clivagem, principalmente em cristais de microclínio e modificam a cor interferindo no canal vermelho do padrão de cor do litotipo.

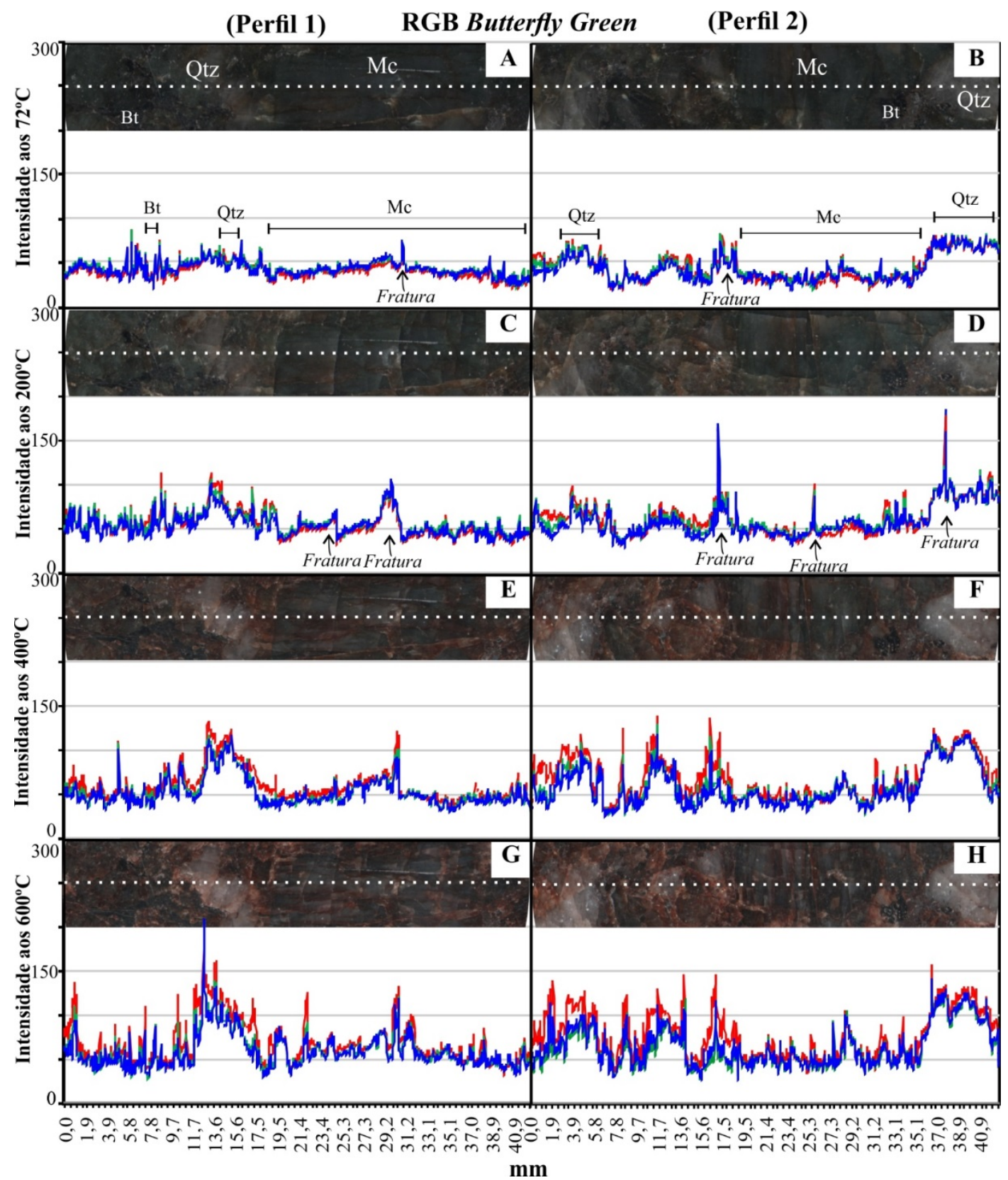

Figura 11 - Leituras dos perfis RGB para o Butterfly Green para diferentes temperaturas. 
Aos $400^{\circ} \mathrm{C}$ (Figuras $11 \mathrm{E}$ e $11 \mathrm{~F}$ ) e aos $600^{\circ} \mathrm{C}$ (Figuras $12 \mathrm{G}$ e $12 \mathrm{H}$ ) a intensidade das leituras RGB para o quartzo sofre um aumento dando um aspecto mais claro ao litotipo o que, por sua vez, é o contrário do que ocorre nos outros dois litotipos (Butterfly Beige e Butterfly Gold).

Os dados mostram que alguns cuidados devem ser tomados ao aplicar estas rochas na construção civil.

A exposição às diferentes e elevadas temperaturas em espaços de tempo relativamente curtos foi uma tentativa de reproduzir os efeitos causados pela insolação nas superfícies dos materiais rochosos estudados quando aplicados em fachadas, por exemplo. Aconselha-se, a partir dos resultados obtidos neste trabalho, que as rochas estudadas (principalmente a variedade Green) devem ser utilizadas em revestimentos de ambientes internos.

Fontes de calor (o sol, no caso da utilização em revestimentos de exteriores) podem acelerar o processo de modificação das cores destes materiais em função da presença de minerais ferro-magnesianos e, principalmente, do $\mathrm{Fe}(\mathrm{OH})_{2}$ que são passíveis de oxidação.

\section{CONCLUSÕES}

Aos $200^{\circ} \mathrm{C}$ a ordem de descaracterização superficial ficou, do mais descaracterizado para o menos descaracterizado, Butterfly Beige $(r=0,5)$, Butterfly Gold $(\mathrm{r}=0,6)$ e Butterfly Green $(\mathrm{r}=0,7)$. Dentre as três rochas, as que apresentaram as maiores descaracterizações aos $400^{\circ} \mathrm{C}$ foram $\mathrm{O}$ Butterfly Green e o Butterfly Beige (ambos com $r=0,5)$, seguidos do Gold $(r=0,6)$. Aos $600{ }^{\circ} \mathrm{C}$ todas as rochas ficaram com coeficientes de correlação iguais a 0,5.

Os valores encontrados para os coeficientes de correlação entre as imagens das rochas ornamentais estudadas expostas às diferentes temperaturas indicam que as rochas, já nos primeiros $200^{\circ} \mathrm{C}$, foram bastante afetadas pela temperatura sendo classificadas com descaracterização moderada.

As alterações estéticas causadas estão associadas à ciclagem térmica (contração e dilatação cíclicas) que, por sua vez, desestrutura a rocha abrindo poros e aumentando sua capacidade de absorção de umidade, quando em processo de arrefecimento, causando oxidação de minerais ferro-magnesianos como nos cristais de biotita e de hiperstênio. Pode ocorrer também a liberação, por histerese, de $\mathrm{Fe}(\mathrm{OH})_{2}$ préexistente em planos de clivagem de minerais como o microclínio.

$\mathrm{O}$ aumento da temperatura, somado à umidade à qual os corpos de prova foram expostos durante o período de arrefecimento de $30 \mathrm{~min}$, acelera o processo de oxidação do Fe. Além disso, a variação da temperatura leva a rocha a uma sucessão de ciclos de dilatação e contração que, por consequência, implica a geração de microfissuras, alargamento dos planos de clivagem dos minerais, bem como ofusca os contatos entre eles facilitando a percolação de fluidos (água) aumentando o grau de oxidação do $\mathrm{Fe}$ ao mesmo tempo em que facilita a disseminação do hidróxido de Fe. Com o passar do tempo, o processo todo conduz a desagregação da rocha.

Os dados mostram que alguns cuidados devem ser tomados ao aplicar estas rochas na construção civil.

Sabe-se que a exposição a diferentes temperaturas em espaços de tempo relativamente curtos, inclusive para resfriamento, é uma tentativa de reproduzir os efeitos causados pela insolação nas superfícies dos materiais rochosos estudados.

Julga-se, a partir dos resultados obtidos neste trabalho, que as rochas estudadas (principalmente a variedade Green) devem ser utilizadas em revestimentos de ambientes de interiores, ou seja, fontes de calor (o sol, no caso da utilização em revestimentos externos) podem acelerar o processo de modificação das cores destes materiais em função da presença de minerais ferro-magnesianos e, principalmente, do $\mathrm{Fe}(\mathrm{OH})_{2}$ que são passíveis de oxidação.

\section{AGRADECIMENTOS}

À Guidoni Mineração Ltda pelo auxílio e cessão das amostras, à CAPES processo 3030/13-0, ao CNPq processo: 141706/2012-0 e ao Centro de Petrologia e Geoquímica do Instituto Superior Técnico de Lisboa, Lisboa, Portugal. 


\section{REFERÊNCIAS}

AIRES-BARROS, L.; GRAÇA, R. C.; VELEZ, A. Dry and wet laboratory tests and thermal fatigue of rocks. Engineering Geology, v. 9, p. 249-265, 1975.

ALKMIN, F. F.; PEDROSA-SOARES, A. C.; NOCE, C. M.; CRUZ, S. C. P. Sobre a evolução tectônica do Orógeno Araçuaí-Congo Ocidental. Geonomos, v. 15, n. 1, p. 24-43, 2007.

ALMEIDA, F. F. M. DE Geologia do Continente Sul Americano: Evolução da Obra de Fernando Marques de Almeida. In: MANTESSO-NETO, V.; BARTORELI, A.; CELSO, D.R.C.; BRITO-NEVES, B.B. (Coords), 211p., 2004.

BOLONINI, T. M. Estudo das aplicações das variedades de um quartzo sienito com hiperstênio, como rochas ornamentais, com auxílio da caracterização tecnológica e das análises de cor e imagem. Rio Claro, 2015. 134 p. Tese de (Doutorado). Instituto de Geociências e Ciências Exatas, Universidade Estadual Paulista.

BOLONINI, T. M.; GODOY, A. M.; SAAR, L. C. A. Geologia e litogeoquímica das rochas graníticas do maciço Capão Bonito e o contexto geológico da sequência vulcanosedimentar Açungui. São Paulo, UNESP. Geociências, v. 32, n. 3, p. 452-470, 2013.

BOLONINI, T. M. \& GODOY, A. M. Caracterização Tecnológica dos Quartzo Sienitos com Hiperstênio Butterfly Beige e Butterfly Green. Geociências, v. 36, n. 3, p. 442-458, 2017.

BOLONINI, T. M.; GODOY, A. M.; BOLONINI, L. C. A. S.; SILVEIRA, L. L. L.; SANTOS, E. Análise de cor em imagens digitais e análise de brilho para rochas ornamentais submetidas ao ataque químico. In: SIMPÓSIO DE ROCHAS ORNAMENTAIS DO NORDESTE IX, João Pessoa, 2016a. Anais... João Pessoa: CETEM.

BOLONINI, T. M.; GODOY, A. M.; BOLONINI, L. C. A. S.; SILVEIRA, L. L. L.; SANTOS, E. Quantificação mineralógica modal macroscópica, em rochas ornamentais submetidas à coloração seletiva por ataque químico, através da classificação supervisionada de imagens. In: SIMPÓSIO DE ROCHAS ORNAMENTAIS DO NORDESTE IX, João Pessoa, 2016b. Anais... João Pessoa: CETEM.

BOLONINI, T. M.; GODOY, A. M.; BOLONINI, L. C. A. S.; SILVEIRA, L. L. L.; SANTOS, E. Uso da correlação entre imagens na classificação da descaracterização superficial de rochas ornamentais submetidas ao ataque químico. In: SIMPÓSIO DE ROCHAS ORNAMENTAIS DO NORDESTE IX. João Pessoa, 2016c. Anais... João Pessoa: CETEM.

COHEN, J. Statistical power analysis for the behavioral sciences. Hillsdale, NJ, Erlbaum, 329, p. 1988.

CPRM. Serviço Geológico do Brasil. Geologia da Folha de Mantena - SE.24-Y-A-VI - Programa Geologia do Brasil - nota explicativa da folha Mantena. Escala 1:100.000. Brasília, 2007.

DANCEY, C. \& REIDY, J. Estatística Sem Matemática para Psicologia: Usando SPSS para Windows. Porto Alegre, Artmed, 2006.

FIGUEIREDO, C.A.M.; FIGUEIREDO, P.; AIRES-BARROS, L.; PINA, P.; RAMOS, V. Texture analysis of images taken from artificially aged Stones: a statistical and structural approach. Restoration of Buildings and Monuments, v 11, n. 4, p. 235-245, 2005.

GRIGGS, D. T. The factor of fatigue in rock exfoliation. Journal of Geology, v. 44, p. 783-796, 1936.

HERAS, M. G. Procesos y formas de deterioro térmico em piedra natural del patrimônio arquitectónico. Madri, 339p., 2005. Tesis Doctoral. Instituto de Geologia Económica Del Consejo Superior de Investigaciones Científicas y $1^{\text {a }}$ Universidad Complutense de Madrid.

MARSHAK, S.; ALKIMI, F. F.; WHITTINGTON, A.;
PEDROSA-SOARES, A. C. Extensional collapse in the Neoproterozoic Araçuaí Orogen, eastern Brazil: a setting for reactivation of asymmetric crenulation cleavage. Journal of Structural Geology, v. 28, p. 129-147, 2006.

MARTINS, V. T. DE S.; TEIXEIRA, W.; NOCE, C. M.; PEDROSA-SOARES, A. C. Sr and Nd Characteristics of Brasiliano/Pan-African Granitoid Plutons of the Araçuaí Orogen, Southeastern Brazil: Tectonic Implications. Gondwana Research, v. 7, n. 1, p. 75-89, 2004.

NOCE, C. M.; PEDROSA-SOARES, A. C.; SILVA, L. C. da; ARMSTRONG, R.; PIUZANA, D. Evolution of polycyclic basement complexes in the Araçuaí Orogen, based on U-Pb SHRIMP data: Implications for Brazil- Africa links in Paleoproterozoic time. Precambrian Research, v. 159, p. 60-78, 2007.

PEDROSA-SOARES, A. C.; NOCE, C. M.; VIDAL, P.H.; MONTEIRO, R.L.B.P.; LEONARDOS, O.H. Toward a new tectonic model for the Late Proterozoic Araçuaí (SE Brazil) - West Congolian (SW Africa) Belt. Journal of South American Science, v. 6, n. 1/2, p. 33-47, 1992.

PEDROSA-SOARES, A. C.; NOCE, C. M.; WIEDEMANN, C.M.; PINTO, C.P. The Araçuaí-West-Congo Orogen in Brazil: an overview of a confined orogen formed during Gondwanaland assembly. Precambrian Research, v. 110, p. 307-323, 2001.

PEDROSA-SOARES, A. C.; CASTAÑEDA, C.; QUEIROGA, C.; GRADIM, C.; BELÉM, J.; RONCATO, J.; NOVO, T.; DIAS, P.; GRADIM, D.; MEDEIROS, S.; JACOBSOHN, T.; BABINSKI, M.; VIEIRA, V. Magmatismo e tectônica do Orógeno Araçuaí no extremo Leste de Minas e Norte do Espírito Santo $\left(18^{\circ}-19^{\circ} \mathrm{S}, 41^{\circ}\right.$ 40³0’W). Geonomos, v. 14, n. 1, 2, p. 97-111, 2006.

PEDROSA-SOARES, A. C.; NOCE, C. M.; ALKIMIM, F. F.; SILVA, L. C. DA; BABINSKI, M., CORDANI, U.; CASTAÑEDA, C. Orógeno Araçuaí: Síntese do Conhecimento 30 anos após Almeida 1977. Geonomos, v. 15, n. 1, p. 1-16, 2007.

RICHTER, D. \& SIMMONS, G. Thermal Expansion Behavior of Igneous Rocks. International Journal of Rock Mechanics and Mining Sciences, v. 11, p. 403-411, 1974.

RONCATO JÚNIOR, J. G. As Suítes Graníticas Tipo-S do norte do Espírito Santo na região das Folhas Ecoporanga, Mantena, Montanha e Nova Venécia. Belo Horizonte, 2009, 103p. Dissertação (Mestrado). 2009. Instituto de Geociências, Universidade Federal de Minas Gerais.

SAAR, L. C. A. Avaliação dos “Granitos” Giallo São Francisco Real, Branco Dallas e Branco Marfim, do município de Barra de São Francisco/ES para aplicação como rocha ornamental e de revestimento. Rio Claro, 2013, 188 p. Dissertação (Mestrado em Geologia Regional). Instituto de Geociências e Ciências Exatas - Universidade Estadual Paulista.

SAAR, L. C. A.; GODOY, A. M.; BOLONINI, T. M. Considerações sobre os granitos Giallo São Francisco Real, Branco Dallas e Branco Marfim, no município de Barra de São Francisco - ES para aplicação como rocha ornamental e de revestimento. São Paulo, UNESP. Geociências, v. 34, n. 1, p. 1-18, 2015.

SOUZA, A. Coeficiente de Correlação de Pearson. Mestrado em Gestão (MBA). Departamento de Matemática da Universidade dos Açores. Portugal (2008). Disponível em: http://www.aurea.uac.pt/pdf_MBA/coef_correl_Pearson.pdf.

TOROK, A. \& HAJPAL, M. Effect of temperature changes on the mineralogy and physical properties of sandstones. A laboratory study. Restoration of Buildings and Monuments, v. 11, n. 4, p. 1-8, 2005. 
TORQUATO, M. F. B.; TORQUATO, J R. F.; FIGUEIREDO, C. A. M.; NOGUEIRA NETO, J. A. N. Estudo dos granitos cearenses "Vermelho Filomena, Meruoca Clássico e Verde Ceará” por análise digital de imagem em câmara com atmosfera satura em $\mathrm{SO}_{2}$. Geonomos. v. 16, n. 2, p. 51-52, 2008.

WINKLER, E. M. Stone in architecture: properties, durability. Springer Verlag, Berlin; New York, xvi, 313 p., 1997.
YATSU, E. The nature of weathering: an introduction. Sozosha: Overseas distributor Maruzen Co., Tokyo, xiii, 624 p., 1988.

Submetido em 13 de novembro de 2015 Aceito em 10 de março de 2017 